\title{
PERENCANAAN WAKTU PROYEK PEMBANGUNAN GEDUNG KAMPUS I UKI TORAJA DENGAN PRIMAVERA PROJECT PLANNER
}

Parea RusanR., MT., Staf Pengajar Teknik Sipil, UKI Toraja

\begin{abstract}
ABSTRAK
Penjadwalan untuk proyek diawali dengan identifikasi aktivitas dan perhitungan volume pekerjaan berdasarkan data primer dan sekunder. Langkah berikutnya adalah melakukan perhitungan durasi berdasarkan koefisien Standar Nasional Indonesia Tentang Analisa Biaya Pekerjaan Konstruksi. Pengolahan data dengan program Primavera Project Planer versi 3.0 yang mempermudah proses monitoring dan controlling serta mempercepat proses updating selama pelaksanaan dilapangan. Output hasil perencanaan adalah berupa tampilan grafis Barchart \& Time schedule yang memperlihatkan aktivitas pekerjaan dalam diagram batang. Schedule Report, yang terdiri dari early start-early finish, late start-late finish. Jaringan Kerja (Network planning) memperlihatkan hubungan saling ketergantungan antar aktivitas pekerjaan yang dihubungkan oleh anak panah dalam kurun waktu kerja yang diprediksikan secara otomatis dengan lebih jelas berikut jalur kritis untuk dimonitor sehingga tidak terjadi keterlambatan. Dengan bantuan program komputer diperoleh hasil waktu pelaksanaan pekerjaan selama 1005 hari dengan penggunaan tenaga kerja sesuai yang tersedia di lapangan.
\end{abstract}

Kata kunci : Precedence Diagram Method (PDM), Barchart Network Planning, Program Primavera Project Planner, \& Time schedule. 


\section{PENDAHULUAN}

\section{Latar Belakang}

Membuat rencana adalah salah satu aspek terpenting dalam tahapan siklus proyek. Setelah perencanaan dirampungkan, akan terus mengikuti proyek di sepanjang penyelesaian sampai akhirnya dan akan digunakan dalam penilaian penyelesaian. Perencanaan memiliki banyak tujuan, menyediakan tinjauan atas orang-orang yang bekerja pada proyek dan aktivitas-aktivitas pekerjaan, serta tata urutan yang diperlukan.

Proyek Pembangunan Gedung Kampus 1 Universitas Kristen Indonesia Toraja memerlukan analisa-analisa secara tepat dan mendetail, sehingga dapat dikelola dengan baik. Perencanaan menajemen proyek bangunan gedung harus dibuat dengan suatu analisis perencanaan yang matang dan memberikan informasi yang jelas akan bangunan yang dirancang.

Kesalahan dalam perencanaan bangunan dapat berakibat kegagalan konstruksi atau keruntuhan, kesalahan penjadwalan waktu dan tenaga kerja berakibat keterlambatan kerja dan kerugian. Walaupun manusia tidak luput dari kesalahan, namun kesalahan ini harus di minimalkan atau dihindarkan. Dengan kemajuan pendidikan seiring dengan kemajuan teknologi membuat kita dapat melakukan analisa perencanaan dan pelaksanaan pembangunan yang terkendali, mampu meminimalkan kesalahan, sehingga dapat menghindari keterlambatan waktu.

Dalam perencanaan proyek yang bersifat kompleks diperlukan suatu perencanaan yang baik supaya pelaksanaannya dapat berjalan dengan lancar, tepat waktu. Pembangunan gedung dengan skala yang besar seperti dalam kegiatan Proyek Pembangunan Gedung Kampus 1 Universitas Kristen Indonesia Toraja memerlukan analisa-analisa secara tepat dan mendetail, sehingga dapat dikelola dengan baik. Perencanaan menajemen proyek bangunan gedung harus dibuat dengan suatu analisis perencanaan yang matang dan memberikan informasi yang jelas akan bangunan yang dirancang.

Untuk memudahkan dalam menyusun jadwal, menganalisa jaringan kerja dan pengelolaan sumber daya digunakan alat bantu komputer yang berupa software Primavera Project Planner sehingga dapat diperoleh penjadwalan waktu pelaksanaan dan jumlah tenaga kerja optimal. Menggunakan Primavera Project Planner dalam proyek konstruksi membantu mulai dari merancang kegiatan proyek, membangun jaringan, mengelola data secara mudah dan cepat. Data dalam proyek dapat diorganisasikan dalam berbagai grup sesuai dengan kebutuhan misalnya berdasarkan aktivitas, sumber daya (resource), dan Tenaga Kerja. Primavera Project Planner dapat digunakan untuk mengumpulkan data-data proyek, kemudian dapat memantau kemajuan proyek dan menampilkan informasi actual tentang proyek setiap saat dibutuhkan. 


\section{Gambaran Umum}

\section{METODE PENELITIAN}

Gedung Kampus UKI Toraja didirikan untuk mengatasi kebutuhan pendidikan pada Universitas Kristen Indonesia Toraja yang semakin meningkat, diharapkan bahwa dengan berdirinya kampus ini dapat memenuhi kebutuhan akan prasarana, ruang kuliah baru dan fasilitas-fasilitas penunjang lainnya. Bangunan terdiri atas 5 (lima) lantai dengan spesifikasi penggunaan sebagai berikut : Basement sebagai tempat parkir; Lantai 1, terdiri dari 1 ruang serba guna +6 ruang kuliah; Lantai 2 , terdiri dari 15 ruang kuliah +1 ruang kantin; Lantai 3, terdiri dari 11 ruang kuliah +2 ruang Kajur +2 ruang Progdi +1 ruang BAAK Fakultas +1 ruang Dosen +1 ruang Dekan +2 ruang Pembantu Dekan; Lantai 4, terdiri dari 8 ruang kuliah +1 ruang Dosen +1 ruang Dekan +1 ruang PD +1 ruang Progdi +1 ruang BAAK Fakultas + 1 ruang BEM; Top floor, ditempati ruang mesin lift dan bak air.

\section{Metodologi Penelitian Dengan Program Primavera Project Planner.}

Pengunaan Program Primavera Project Planner pada perencanaan waktu dan tenaga kerja sebagai sarana dalam perencanaan, dalam hal ini data volume pekerjaan/kegiatan dan koefisien pekerjaan yang ditentukan berdasarkan Standar Nasional (SNI) yang telah ditetapkan menjadi bahan dasar atau acuan yang dalam perencanaan penelitian ini. Adapun skema metodologi penelitian yang digunakan adalah sebagai berikut :

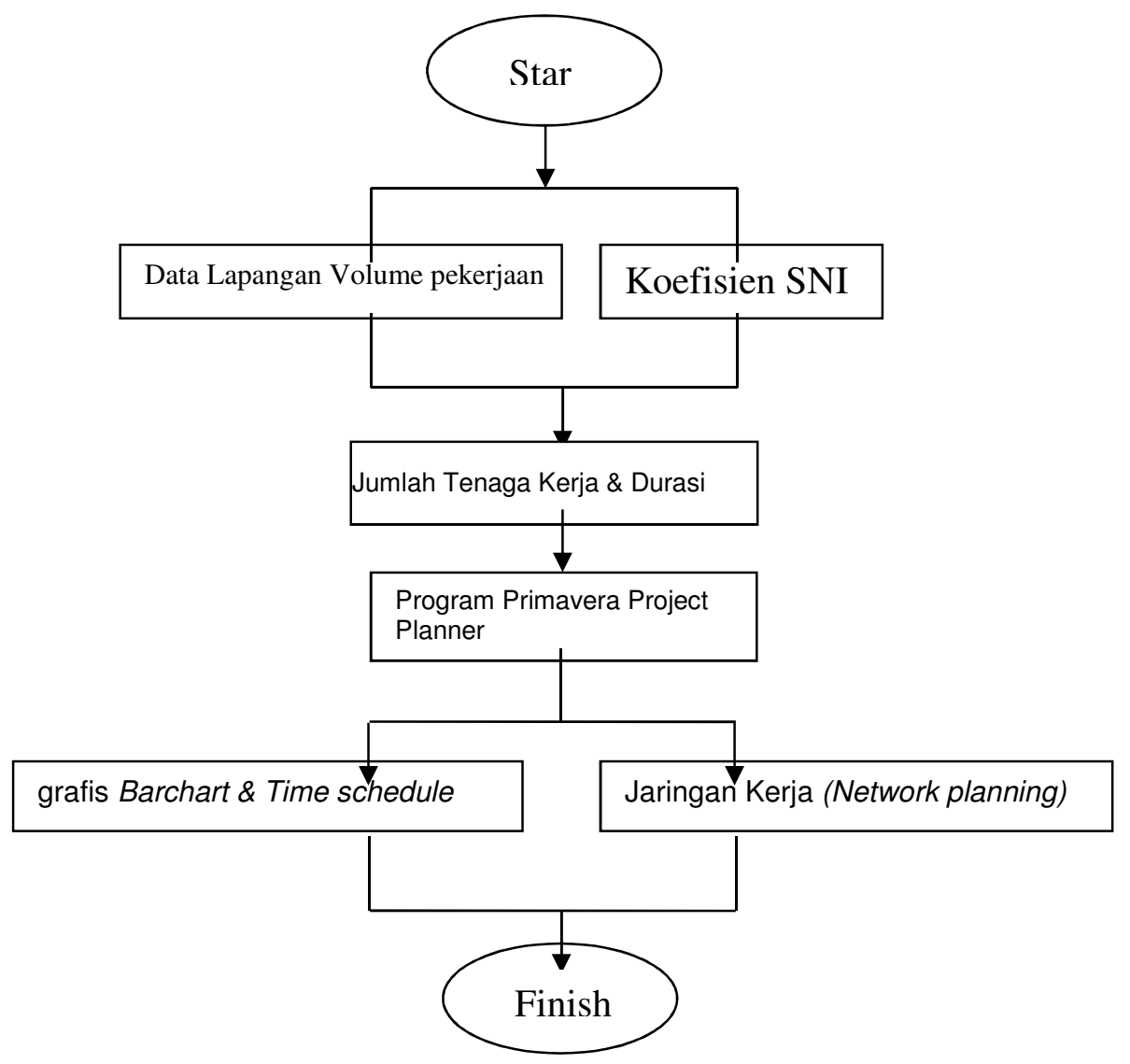

Gbr. 3.4 Skema metodologi penelitian mengunakan Program Primavera Project Planner 


\section{HASIL DAN PEMBAHASAN}

\section{Daftar Volume pekerjaan}

\section{Daftar Pekerjaan Lantai 2}

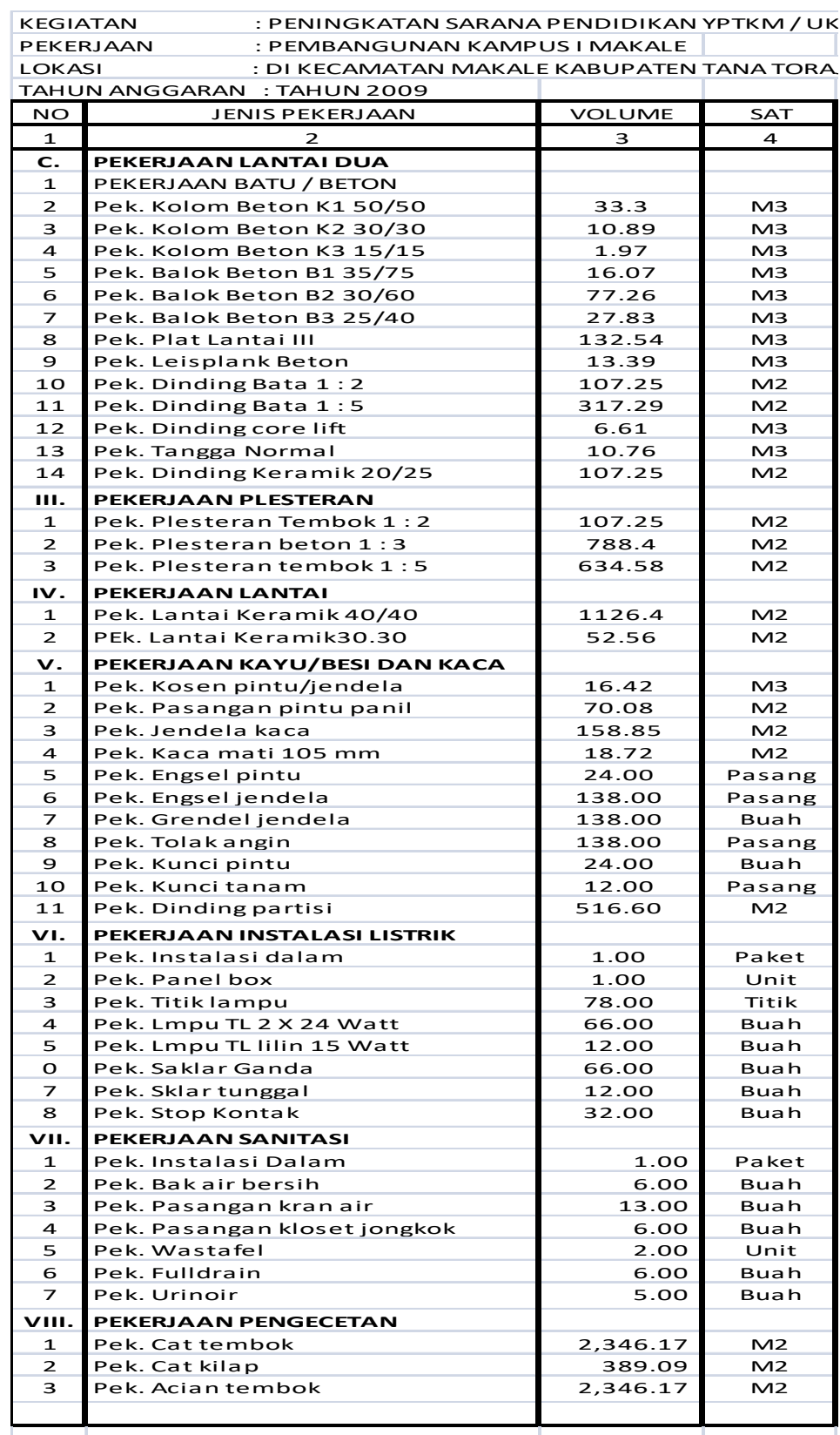

Tabel 4.1 Daftar Pekerjaan Lantai 2 
2. Daftar Pekerjaan Lantai 3

\begin{tabular}{|c|c|c|c|}
\hline \multirow{2}{*}{$\begin{array}{l}\text { KEGIATAN } \\
\text { PEKERJAAN }\end{array}$} & \multicolumn{3}{|c|}{ : PENINGKATAN SARANA PENDIDIKAN YPTKM / UKI TC } \\
\hline & : PEMBANGUNAN KAMP & MAKALE & \\
\hline LOKA & \multicolumn{3}{|c|}{ : DI KECAMATAN MAKALE KABUPATEN TANA TORAJA } \\
\hline \multicolumn{4}{|c|}{ TAHUN ANGGARAN : TAHUN 2009 : } \\
\hline NO & JENIS PEKERJAAN & VOLUME & SATUAN \\
\hline 1 & 2 & 3 & 4 \\
\hline c. & PEKERJAAN LANTAI TIGA & & \\
\hline 1 & PEKERJAAN BATU / BETON & & \\
\hline 2 & Pek. Kolom Beton K1 50/50 & 33.30 & M3 \\
\hline 3 & Pek. Kolom Beton K2 30/30 & 10.89 & M3 \\
\hline 4 & Pek. Kolom Beton K3 15/15 & 1.97 & M3 \\
\hline 5 & Pek. Balok Beton B1 35/75 & 16.07 & M3 \\
\hline 6 & Pek. Balok Beton B2 30/60 & 77.26 & M3 \\
\hline 7 & Pek. Balok Beton B3 25/40 & 27.83 & M3 \\
\hline 8 & Pek. Plat Lantai IV & 132.54 & M3 \\
\hline 9 & Pek. Leisplank Beton & 13.39 & M3 \\
\hline 10 & Pek. Dinding Bata $1: 2$ & 107.25 & M2 \\
\hline 11 & Pek. Dinding Bata $1: 5$ & 317.29 & M2 \\
\hline 12 & Pek. Dinding core lift & 6.61 & M3 \\
\hline 13 & Pek. Tangga Normal & 10.76 & M3 \\
\hline 14 & Pek. Dinding Keramik 20/25 & 107.25 & M2 \\
\hline III. & PEKERJAAN PLESTERAN & & \\
\hline 1 & Pek. Plesteran Tembok $1: 2$ & 107.25 & M2 \\
\hline 2 & Pek. Plesteran beton $1: 3$ & 788.40 & M2 \\
\hline 3 & Pek. Plesteran tembok $1: 5$ & 634.58 & M2 \\
\hline IV. & PEKERJAAN LANTAI & & \\
\hline 1 & Pek. Lantai Keramik 40/40 & $1,126.40$ & M2 \\
\hline 2 & PEk. Lantai Keramik30.30 & 52.56 & M2 \\
\hline v. & PEKERJAAN KAYU/BESI DAN KACA & & \\
\hline 1 & Pek. Kosen pintu/jendela & 16.42 & Mз \\
\hline 2 & Pek. Pasangan pintu panil & 70.08 & M2 \\
\hline 3 & Pek. Jendela kaca & 158.85 & M2 \\
\hline 4 & Pek. Kaca mati 105 mm & 18.72 & M2 \\
\hline 5 & Pek. Engsel pintu & 24.00 & Pasang \\
\hline 6 & Pek. Engsel jendela & 138.00 & Pasang \\
\hline 7 & Pek. Grendel jendela & 138.00 & Buah \\
\hline 8 & Pek. Tolak angin & 138.00 & Pasang \\
\hline 9 & Pek. Kunci pintu & 24.00 & Buah \\
\hline 10 & Pek. Kunci tanam & 12.00 & Pasang \\
\hline 11 & Pek. Dinding partisi & 516.60 & M2 \\
\hline VI. & PEKERJAAN INSTALASI LISTRIK & & \\
\hline 1 & Pek. Instalasi dalam & 1.00 & Paket \\
\hline 2 & Pek. Panel box & 1.00 & Unit \\
\hline 3 & Pek. Titik lampu & 78.00 & Titik \\
\hline 4 & Pek. Lmpu TL $2 \times 24$ Watt & 66.00 & Buah \\
\hline 5 & Pek. Lmpu TL lilin 15 Watt & 12.00 & Buah \\
\hline $\mathrm{o}$ & Pek. Saklar Ganda & 62.00 & Buah \\
\hline 7 & Pek. Sklar tunggal & 12.00 & Buah \\
\hline 8 & Pek. Stop Kontak & 32.00 & Buah \\
\hline VII. & PEKERJAAN SANITASI & & \\
\hline 1 & Pek. Instalasi Dalam & 1.00 & Paket \\
\hline 2 & Pek. Bakair bersih & 6.00 & Buah \\
\hline 3 & Pek. Pasangan kran air & 13.00 & Buah \\
\hline 4 & Pek. Pasangan kloset jongkok & 6.00 & Buah \\
\hline 5 & Pek. Wastafel & 2.00 & Unit \\
\hline 6 & Pek. Fulldrain & 6.00 & Buah \\
\hline 7 & Pek. Urinoir & 5.00 & Buah \\
\hline VIII. & PEKERJAAN PENGECETAN & & \\
\hline 1 & Pek. Cat tembok & $2,346.17$ & M2 \\
\hline 2 & Pek. Cat kilap & 389.09 & M2 \\
\hline 3 & Pek. Acian tembok & $2,346.17$ & M2 \\
\hline
\end{tabular}

Tabel 4.2 Daftar Pekerjaan Lantai 3 


\section{Daftar Pekerjaan Lantai 4}

\begin{tabular}{|c|c|c|c|}
\hline NO & JENIS PEKERJAAN & VOLUME & SAT \\
\hline 1 & 2 & 3 & 4 \\
\hline E. & PEKERJAAN LANTAI EMPA & & \\
\hline I. & PEKERJAAN BATU / BETON & & \\
\hline 1. & Pek. Kolom Beton K1 50/50 & 33.30 & $M^{3}$ \\
\hline 2. & Pek. Kolom Beton K2 30/30 & 10.89 & $M^{3}$ \\
\hline 3. & Pek. Kolom K3 15/15 & 1.97 & $M^{3}$ \\
\hline 4. & Pek. Balok Beton B1 35/75 & 16.07 & $M^{3}$ \\
\hline 5. & Pek. Balok Beton B2 30/60 & 77.26 & $M^{3}$ \\
\hline 6. & Pek. Balok Beton B3 25/40 & 27.83 & $M^{3}$ \\
\hline 7. & Pek. Plat Lantai III & 132.54 & $M^{3}$ \\
\hline 8. & Pek. Leisplank Beton & 13.39 & $M^{3}$ \\
\hline 9. & Pek. Dinding Bata $1: 2$ & 107.25 & $M^{2}$ \\
\hline 10. & Pek. Dinding Bata $1: 5$ & 317.29 & $M^{2}$ \\
\hline 11. & Pek. Dinding Core Lift & 6.61 & $M^{3}$ \\
\hline 12. & Pek. Tangga Normal & 10.76 & $\mathrm{M}^{3}$ \\
\hline 13. & Pek. Dinding Keramik 20/25 & 107.25 & $M^{2}$ \\
\hline III. & PEKERJAAN PLESTERAN & & \\
\hline 1. & Pek. Plesteran Tembok $1: 2$ & 107.25 & $M^{2}$ \\
\hline 2. & Pek. Plesteran Beton $1: 3$ & 788.4 & $M^{2}$ \\
\hline 3. & Pek. Plesteran Tembok $1: 5$ & 634.58 & $M^{2}$ \\
\hline IV. & PEKERJAAN LANTAI & & \\
\hline 1. & Pek. Lantai Keramik 40/40 & $1,126.40$ & $M^{2}$ \\
\hline 2. & Pek. Lantai Keramik 30/30 & 52.56 & $M^{2}$ \\
\hline V. & \multicolumn{2}{|c|}{ PEKERJAAN KAYU/BESI DAN KACA } & \\
\hline 1. & Pek. Kosen Pintu/Jendela & 16.02 & $M^{3}$ \\
\hline 2. & Pek. Pasangan Pintu Panil & 63.82 & $M^{2}$ \\
\hline 3. & Pek. Jendela Kaca & 161.25 & $M^{2}$ \\
\hline 4. & Pek. Kaca Mati $10 \mathrm{~mm}$ & 18.72 & $M^{2}$ \\
\hline 5. & Pek. Engsel Pintu & 21.00 & Pasang \\
\hline 6. & Pek. Engsel Jendela & 138.00 & Pasang \\
\hline 7. & Pek. Grendel Jendela & 138.00 & Buah \\
\hline 8. & Pek. Tolak Angin & 138.00 & Pasang \\
\hline 9. & Pek. Kunci Pintu & 21.00 & Buah \\
\hline 10. & Pek. Kunci Tanam & 44.00 & Pasang \\
\hline 11. & Pek. Dinding Partisi & 516.60 & $M^{2}$ \\
\hline VI. & PEKERJAAN INSTALASI LIST & & \\
\hline 1. & Pek. Instalasi Dalam & 1.00 & Paket \\
\hline 2. & Pek. Panel Box & 1.00 & Unit \\
\hline 3. & Pek. Titik Lampu & 78.00 & Titik \\
\hline 4. & Pek. Lampu TL $2 \times 20$ Watt & 66.00 & Buah \\
\hline 5. & Pek. Lampu TL Lilin 15 Watt & 12.00 & Buah \\
\hline 6. & Pek. Saklar Ganda & 66.00 & Buah \\
\hline 7. & Pek. Saklar Tunggal & 12.00 & Buah \\
\hline 8. & Pek. Stop Kontak & 28.00 & Buah \\
\hline
\end{tabular}

Tabel 4.3 Daftar Pekerjaan Lantai 4 
4. Daftar Pekerjaan Top Floor

\begin{tabular}{|c|c|c|c|}
\hline NO & JENIS PEKERJAAN & VOLUME & SAT \\
\hline 1 & 2 & 3 & 4 \\
\hline F. & PEKERJAAN TOP FLOOR & & \\
\hline I. & PEKERJAAN BATU / BETON & & \\
\hline 1. & Pek. Kolom Beton K2 30/30 & 6.13 & $\mathrm{M}^{3}$ \\
\hline 2. & Pek. Kolom Beton K2 15/15 & 0.65 & $\mathrm{M}^{3}$ \\
\hline 3. & Pek. Ringbalok 20/25 & 3.24 & $M^{3}$ \\
\hline 4. & Pek. Dinding Bata $1: 5$ & 75.60 & $M^{3}$ \\
\hline 5. & Pek. Dinding Core Lift & 6.61 & $M^{3}$ \\
\hline 6. & Pek. Tangga Normal & 3.46 & $\mathrm{M}^{3}$ \\
\hline 7. & Pek. Leisplank Beton & 21.00 & $M^{3}$ \\
\hline II. & \multicolumn{2}{|l|}{ PEKERJAAN PLESTERAN } & \\
\hline 1. & Pek. Plesteran Beton $1: 3$ & 350.00 & $M^{2}$ \\
\hline 2. & Pek. Plesteran Tembok $1: 5$ & 181.44 & $\mathrm{M}^{2}$ \\
\hline III. & \multicolumn{2}{|c|}{ PEKERJAAN KAYU/BESI DAN KACA } & \\
\hline 1. & Pek. Kosen Pintu/Jendela & 7.50 & $M^{3}$ \\
\hline 2. & Pek. Pasangan Pintu Panil & 1.68 & $M^{2}$ \\
\hline 3. & Pek. Jendela Kaca & 22.00 & $M^{2}$ \\
\hline 4. & Pek. Kuda-Kuda/Gording & & \\
\hline 5. & Pek. Leisplank Bayam 3/25 & 91.20 & \\
\hline 6. & Pek. Atap & 360.07 & $M^{2}$ \\
\hline 7. & Npk. Nok Atap & 24.00 & $M^{\prime}$ \\
\hline 8. & Pek. Balok Plafon & 516.60 & $M^{2}$ \\
\hline 9. & Pek. Plafon & 516.60 & $M^{2}$ \\
\hline IV. & \multicolumn{2}{|c|}{ PEKERJAAN INSTALASI LISTRIK } & \\
\hline 1. & Pek. Instalasi Dalam & 1.00 & Paket \\
\hline 2. & Pek. Panel Box & 1.00 & Unit \\
\hline 3. & Pek. Titik Lampu & 25.00 & Titik \\
\hline 4. & Pek. Lampu TL 2 x 20 Watt & 20.00 & Buah \\
\hline 5. & Pek. Lampu TL Lilin 15 Watt & 5.00 & Buah \\
\hline 6. & Pek. Saklar Ganda & 2.00 & Buah \\
\hline 7. & Pek. Saklar Tunggal & 1.00 & Buah \\
\hline 8. & Pek. Stop Kontak & 2.00 & Buah \\
\hline V. & \multicolumn{2}{|l|}{ PEKERJAAN PENGECETAN } & \\
\hline 1. & Pek. Cat Tembok & 531.44 & $\mathrm{M}^{2}$ \\
\hline 2. & Pek. Cat Kilap & 76.31 & $M^{2}$ \\
\hline 3. & Pek. Acian Tembok & 531.44 & $M^{2}$ \\
\hline 4. & Pek. Cat Atap & 360.07 & $M^{2}$ \\
\hline
\end{tabular}

Tabel 4.4 Daftar Pekerjaan Top Floor 


\section{Daftar Rekap Rencana}

\begin{tabular}{|c|c|c|c|}
\hline NO & JENIS PEKERJAAN & VOLUME & SAT \\
\hline 1 & PEKERJAAN PENDAHULUAN & & \\
\hline 1 & Pek. Bongkar bangunan Iama & 1.00 & Paket \\
\hline 2 & Pek. Pengukuran/Bouwplank & 1.00 & Paket \\
\hline 3 & Pek. Pembuatan Direksikeet & 1.00 & Paket \\
\hline 4 & Pek. Keamanan Pekerjaan & 1.00 & Paket \\
\hline 5 & Pek. Administrasi dan Dokumen & 1.00 & Paket \\
\hline 6 & Pek. Mobilisasi Alat & 1.00 & Paket \\
\hline 7 & Pek. Persiapan P3K & 1.00 & Paket \\
\hline II & PEKERJAAN TANAH & & \\
\hline 1 & Pek. Pengerukan Tanah & $1,668.38$ & $\mathrm{~m}^{3}$ \\
\hline 2 & Pek. Galian Tanah pondasi & 501.80 & $\mathrm{~m}^{3}$ \\
\hline 3 & Pek. Timbunan kembali & 158.52 & $\mathrm{~m}^{3}$ \\
\hline 4 & Pek. Urugan pasir & 106.42 & $\mathrm{~m}^{3}$ \\
\hline & Pek. Urugan tanah & 175.18 & $\mathrm{~m}^{3}$ \\
\hline III & PEKERJAAN BATU/BETON & & \\
\hline 1 & Pek. Pasangan batu kosong & 115.74 & $\mathrm{~m}^{3}$ \\
\hline 2 & Pek. Pondasi batu gunung $1: 4$ & 173.61 & $\mathrm{~m}^{3}$ \\
\hline 3 & Pek. Pondasi poorplat & 28.70 & $\mathrm{~m}^{3}$ \\
\hline 4 & Pek. Sloof beton 35/50 & 84.28 & $\mathrm{~m}^{3}$ \\
\hline 5 & Pek. Kolom Beton K1 50/50 & 193.07 & $\mathrm{~m}^{3}$ \\
\hline 6 & Pek. Kolom Beton K2 30/30 & 60.03 & $\mathrm{~m}^{3}$ \\
\hline & Pek. Kolom Beton K3 15/15 & 10.79 & \\
\hline 7 & Pek. Balok Beton B1 35/75 & 85.07 & $\mathrm{~m}^{3}$ \\
\hline 8 & Pek. Balok Beton B2 30/60 & 382.30 & $\mathrm{~m}^{3}$ \\
\hline 9 & Pek. Balok Beton B3 25/40 & 166.77 & $\mathrm{~m}^{3}$ \\
\hline 10 & Pek. Plat lantai Beton & 786.45 & $\mathrm{~m}^{3}$ \\
\hline 11 & Pek. Leisplank Beton & 76.43 & $\mathrm{~m}^{3}$ \\
\hline 12 & Pek. Dinding Bata $1: 2$ & 550.28 & $\mathrm{~m}^{3}$ \\
\hline 13 & Pek. Dinding Bata $1: 5$ & $3,065.91$ & $\mathrm{~m}^{3}$ \\
\hline 14 & Pek. Dinding cor lift & 43.48 & $\mathrm{~m}^{3}$ \\
\hline & Pek. Dinding keramik 20/25 & 429.00 & \\
\hline 15 & Pek. Tangga Normal & 56.50 & $\mathrm{~m}^{3}$ \\
\hline IV & PEKERJAAN PLESTERAN & & \\
\hline & Pek. Plesteran tembok $1: 2$ & 671.55 & $\mathrm{~m}^{3}$ \\
\hline & Pek. Plesteran tembok $1: 3$ & $5,480.72$ & $\mathrm{~m}^{3}$ \\
\hline & Pek. Plesteran tembok $1: 5$ & $6,162.06$ & $\mathrm{~m}^{3}$ \\
\hline $\mathrm{V}$ & PEKERJAAN LANTAI & & \\
\hline & Pek. Lapisan pasir urug & 135.58 & $\mathrm{~m}^{3}$ \\
\hline & Pek. Lantai beton cor & 135.58 & $\mathrm{~m}^{3}$ \\
\hline & Pek. Lantai keramik 40/40 & $5,579.75$ & \\
\hline & Pek. Lantai keramik 30/30 & 210.24 & \\
\hline
\end{tabular}

\begin{tabular}{|c|c|c|c|}
\hline $\mathrm{VI}$ & PEKERJ AAN KAYU,BESI dan KACA & & \\
\hline 1 & Pek. Kusen pintu/jendela & 73.89 & $\mathrm{~m}^{3}$ \\
\hline 2 & Pek. Pasangan pintu panil & 306.46 & $\mathrm{~m}^{2}$ \\
\hline 3 & Pek. Terali pengaman jendela & 8.10 & $\mathrm{~m}^{2}$ \\
\hline 4 & Pek. Ensel pintu & 116.50 & Pasang \\
\hline 5 & Pek. Kunci pintu & 107.00 & Unit \\
\hline & pek. Jendela kaca & 640.64 & $\mathrm{~m}^{2}$ \\
\hline & Pek. Kaca Mati 5 mm & 247.65 & $\mathrm{~m}^{2}$ \\
\hline & Pek.Roolingdoor & 90.00 & $\mathrm{~m}^{2}$ \\
\hline & Pek. Engsel Jendela & 638.45 & Pasang \\
\hline & Pek. Grendel jendela & 696.00 & Buah \\
\hline & Pek. Tolak angin & 696.00 & Pasang \\
\hline & Pek. Kunci tanam & 86.00 & Buah \\
\hline VII & PEKERJAAN INSTALASI LISTRIK & & \\
\hline 1 & Pek. Instalasi dalam & 7.00 & Paket \\
\hline 2 & Pek. Panel Box & 7.00 & Unit \\
\hline 3 & Pek. Titik Lampu & 419.00 & Titik \\
\hline 4 & Pek. Lampu TL $2 \times 20$ watt & 347.00 & Buah \\
\hline 5 & Pek. Lampu TL lilin 15 watt & 72.00 & Buah \\
\hline 6 & Pek. Saklar Ganda & 216.00 & Buah \\
\hline 7 & Pek. Saklar Tunggal & 56.00 & Buah \\
\hline 8 & Pek. Stop kontak & 100.00 & Buah \\
\hline VIII & PEKERJAAN PENGECETAN & & \\
\hline & Pek. Cat tembok & $16,342.51$ & $\mathrm{~m}^{2}$ \\
\hline & Pek. Cat kilap & $2,285.50$ & $\mathrm{~m}^{2}$ \\
\hline & Pek. Acian tembok & $13,996.34$ & $\mathrm{~m}^{2}$ \\
\hline & Pek. Cat Plafon & 526.50 & $\mathrm{M}^{2}$ \\
\hline & Pek. Cat Atap & 648.00 & $M^{2}$ \\
\hline Vii & PEKERJAAN SANITASI & & \\
\hline 1 & Pek. Instalasi dalam & 7.00 & Paket \\
\hline 2 & Pek.Bakair bersih & 26.00 & Buah \\
\hline 3 & Pek. Pasangan kran air & 51.00 & Buah \\
\hline 4 & Pek. Pasangan kloset jongkok & 26.00 & Buah \\
\hline 5 & Pek. Wastafel & 22.00 & Unit \\
\hline 6 & Pek.Fuldrain & 26.00 & Buah \\
\hline 7 & Pek. Urinoir & 15.00 & Buah \\
\hline 1 & PEKERJAAN ELEKTRIKAL & & \\
\hline 1 & Pek. Hydrant & 1.00 & Paket \\
\hline 2 & Pek. Penyedian tabung pemadam & 15.00 & Paket \\
\hline 3 & Pek. Lift & 2.00 & Unit \\
\hline II & PEKERJAAN KEAMANAN & & \\
\hline 1 & Pek. Penangkal petir & 1.00 & Paket \\
\hline 2 & Pek. Pos Satpam & 2.00 & Unit \\
\hline III & PEKERJAAN LANDSCAPE & & \\
\hline 1 & Pek. Penataan halaman & 1.00 & Paket \\
\hline 2 & Pek. Saluran air hujan & 1.00 & Paket \\
\hline
\end{tabular}

Tabel 4.6 Daftar Pekerjaan Rekap

\section{Data Jumlah Tenaga Kerja.}


Adapun jumlah tenaga kerja yang ada dilapangan sesuai dengan data yang ada (lihat lampiran Absen tenaga kerja Pembangunan Kampus 1 UKI Toraja) terdiri atas Koordintor Tenaga Kerja 1 orang, Kepala Tukang kayu 1 orang, Kepala tukang batu 1 orang, Kepala Tukang Batu Besi 2 orang, Tukang Kayu 9 orang, Tukang Batu 12 orang yang terbagi dua bagian yaitu Tukang Batu 4 orang dan Tukang Biasa 8 orang, buruh 14 yang terbagi dua bagian Buruh Terampil 11 orang dan buruh 3, maka Jumlah tenaga kerja keseluruhan adalah 40 orang.

Dalam melakukan proses pekerjaan keseharian sering kali terjadi ketidak hadiran dengan berbagai alasan seperti sakit, faktor budaya, keadaan postmejure (kerusuhan politik) dan lain-lain yang tentunya mempengaruhi kinerja yang ada sehingga dampak pada keterlambatan waktu penyelesaian pekerjaan.

\section{Analisa Durasi dan Alokasi Tenaga Kerja Berdasarkan SNI 03-2002.}

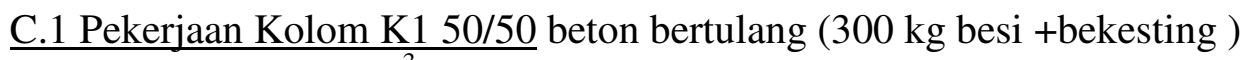
Volume $=33.3 \mathrm{~m}^{3}$

${ }^{1}$ Koefisien SNI untuk $1 \mathrm{~m}^{3}$ membuat kolom beton bertulang

$\begin{array}{llll}\text { Pekerja } & =7.30 \mathrm{OH} & \text { Tukang batu } & =0.35 \mathrm{OH} \\ \text { Tukang kayu } & =3.30 \mathrm{OH} & \text { Tukang besi } & =2.10 \mathrm{OH} \\ \text { Kepala Tukang } & =0.57 \mathrm{OH} & \text { Mandor } & =0.25 \mathrm{OH}\end{array}$

Jumlah $(\Sigma)$ Koef. SNI $=7.30+3.30+0.57+0.35+2.10+0.25=13.87$

Kapasitas $=\frac{1}{\Sigma \text { koef.SNI }}=\frac{1}{13.87}=0.07 \mathrm{~m}^{3}$ /org.hari

Jumlah Tenaga Kerja ( $\Sigma T k$ ) yang diperlukan harus diasumsikan agar kita dapat menghitung durasi pekerjaan yang digunakan untuk menyelesaikan pekerjaan kolom K1 dengan volume tersebut diatas.

Jika Jumlah Tenaga Kerja $(\Sigma T \mathrm{Tk})=22$ orang, maka dibutuhkan jumlah:

$$
\begin{aligned}
& \text { Pekerja }\left(\mathrm{f}_{1}\right)=\frac{\text { Koef Peker ja }}{\Sigma \text { koef. } \text {.SNI }} \times \Sigma \mathrm{Tk}=\frac{7.30}{13.87} \times 22=12 \text { orang } \\
& \text { Tukang batu }=\frac{\text { Koef } \text { T.batu }}{\Sigma \text { koef.SNI }} \times \Sigma \mathrm{Tk}=\frac{0.35}{13.87} \times 22=1 \text { orang } \\
& \text { Tukang kayu }=\frac{\text { Koef T.kayu }}{\Sigma \text { koef.SNI }} \times \Sigma \mathrm{Tk}=\frac{3.30}{13.87} \times 22=5 \text { orang } \\
& \text { Tukang besi }=\frac{\text { Koef besi }}{\Sigma \text { koef.SNI }} \times \Sigma \mathrm{Tk}=\frac{2.10}{13.87} \times 22=3 \text { orang } \\
& \text { Kepala Tukang }=\frac{\text { Koef.Kep.Tukang }}{\Sigma \text { koef.SNI }} \times \Sigma \mathrm{Tk}=\frac{0.57}{13.87} \times 22=1 \text { orang } \\
& \text { Mandor }=\frac{\text { Koef } \text { Mandor }}{\Sigma \text { koef.SNI }} \times \Sigma \mathrm{Tk}=\frac{0.25}{13.87} \times 22=0.4 \text { orang }
\end{aligned}
$$

Durasi pekerjaan yang diperlukan untuk menyelesaikannya adalah :

$$
\text { Durasi Pekerjaan }=\frac{V}{\Sigma T k X \text { Kap }} \quad=\frac{33.30}{22 \times 0.07}=21 \text { Hari }
$$

Pekerjaan Kolom Beton K2 30/30 beton bertulang (300 kg besi +bekesting )

Volume $=10.89 \mathrm{~m}^{3}$

Koefisien SNI untuk $1 \mathrm{~m}^{3}$ membuat kolom beton bertulang

$$
\begin{aligned}
& \text { Pekerja }=7.30 \mathrm{OH} \quad \text { Tukang batu }=0.35 \mathrm{OH} \\
& \text { Tukang kayu }=3.30 \mathrm{OH} \quad \text { Tukang besi }=2.10 \mathrm{OH} \\
& \text { Kepala Tukang }=0.57 \mathrm{OH} \quad \text { Mandor }=0.25 \mathrm{OH} \\
& \text { Jumlah }(\Sigma) \text { Koef. SNI }=\quad 7.30+3.30+0.57+0.35+2.10+0.25=13.87 \\
& \text { Kapasitas }=\frac{1}{\Sigma \text { koef.SNI }}=\frac{1}{13.87}=0.07 \mathrm{~m}^{3} \text { /org.hari }
\end{aligned}
$$

\footnotetext{
${ }^{1}$ Badan Standarisasi Nasional(Bsn), SNI 03-2002 Kumpulan Analisa Biaya Konstruksi (ABK) Bangunan Gedung Dan Perumahan, 2002, Hal.28
} 
Jumlah Tenaga Kerja ( $\Sigma T k)$ yang diperlukan harus asumsikan di agar kita dapat menghitung durasi pekerjaan yang digunakan untuk menyelesaikan pekerjaan kolom K2 dengan volume tersebut diatas.

Jika Jumlah Tenaga Kerja $(\Sigma T k)=19$ orang, maka dibutuhkan jumlah:

$$
\begin{aligned}
& \text { Pekerja }\left(\mathrm{f}_{1}\right)=\frac{\text { Koef Pekerja }}{\Sigma \text { koef } . \text { SNI }} \times \Sigma \mathrm{Tk}=\frac{7.30}{13.87} \times 19=10 \text { orang } \\
& \text { Tukang batu }=\frac{\text { Koef T.batu }}{\Sigma \text { koef.SNI }} \times \Sigma \mathrm{Tk}=\frac{0.35}{13.87} \times 19=0.4 \text { orang } \\
& \text { Tukang kayu }=\frac{\text { Koef T.kayu }}{\Sigma \text { koef } . S N I} \times \Sigma \mathrm{Tk}=\frac{3.30}{13.87} \times 19=5 \text { orang } \\
& \text { Tukang besi }=\frac{\text { Koef besi }}{\Sigma \text { koef } . S N I} \times \Sigma T k=\frac{2.10}{13.87} \times 19=3 \text { orang } \\
& \text { Kepala Tukang }=\frac{\text { Koef.Kep.Tukang }}{\Sigma \text { koef.SNI }} \times \Sigma \mathrm{Tk}=\frac{0.57}{13.87} \times 19=1 \text { orang } \\
& \text { Mandor }=\frac{\text { Koef Mandor }}{\Sigma \text { koef } . S N I} \times \Sigma T k=\frac{0.25}{13.87} \times 19=0.4 \text { orang }
\end{aligned}
$$

Durasi pekerjaan yang diperlukan untuk menyelesaikannya adalah :

$$
\text { Durasi Pekerjaan }=\frac{V}{\Sigma T k X \text { Kap }}=\frac{10.89}{19 \times 0.07}=8 \text { Hari }
$$

\section{C.7 Pek. Plat Lantai III}

Volume $=132.54 \mathrm{~m}^{3}$

Koefisien SNI untuk $1 \mathrm{~m}^{3}$ membuat kolom beton bertulang

$\begin{array}{llll}\text { Pekerja } & =5.60 \mathrm{OH} & \text { Tukang batu } & =1.40 \mathrm{OH} \\ \text { Tukang kayu } & =0.35 \mathrm{OH} & \text { Tukang besi } & =0.41 \mathrm{OH} \\ \text { Kepala Tukang } & =2.30 \mathrm{OH} & \text { Mandor } & =0.20 \mathrm{OH}\end{array}$

Jumlah $(\Sigma)$ Koef. SNI $=5.60+0.35+2.30+1.40+0.41+0.20=10.26$

Kapasitas $=\frac{1}{\Sigma \text { koef } . S N I}=\frac{1}{10.26}=0.10 \mathrm{~m}^{3}$ /org.hari

Jumlah Tenaga Kerja ( $\Sigma T \mathrm{~T})$ yang diperlukan harus asumsikan di agar kita dapat menghitung durasi pekerjaan yang digunakan untuk menyelesaikan pekerjaan Plat Lantai III dengan volume tersebut diatas.

Jika Jumlah Tenaga Kerja $(\Sigma T k)=38$ orang , maka dibutuhkan jumlah:

$$
\begin{aligned}
& \text { Pekerja }\left(\mathrm{f}_{1}\right)=\frac{\text { Koef Peker ja }}{\Sigma \text { koef } . \text { SNI }} \times \Sigma \mathrm{Tk}=\frac{7.30}{13.87} \times 38=21 \text { orang } \\
& \text { Tukang batu }=\frac{\text { Koef } \text { T.batu }}{\Sigma \text { koef.SNI }} \times \Sigma \mathrm{Tk}=\frac{0.35}{13.87} \times 38=1 \text { orang } \\
& \text { Tukang kayu }=\frac{\text { Koef } \text {.kayu }}{\Sigma \text { koef.SNI }} \times \Sigma \mathrm{Tk}=\frac{3.30}{13.87} \times 38=9 \text { orang } \\
& \text { Tukang besi }=\frac{\text { Koef besi }}{\Sigma \text { koef.SNI }} \times \Sigma \mathrm{Tk}=\frac{2.10}{13.87} \times 38=5 \text { orang } \\
& \text { Kepala Tukang }=\frac{\text { Koef.Kep.Tukang }}{\Sigma \text { koef.SNI }} \times \Sigma \mathrm{Tk}=\frac{0.57}{13.87} \times 38=2 \text { orang } \\
& \text { Mandor }=\frac{\text { Koef Mandor }}{\Sigma \text { koef.SNI }} \times \Sigma \mathrm{Tk}=\frac{0.25}{13.87} \times 38=1 \text { orang }
\end{aligned}
$$

Durasi pekerjaan yang diperlukan untuk menyelesaikannya adalah :

$$
\text { Durasi Pekerjaan }=\frac{V}{\Sigma T k X \text { Kap }} \quad=\frac{10.89}{38 \times 0.10}=36 \text { Hari }
$$

Untuk memudahkan analisa selanjutnya dapat dilihat pada Table Analisa Durasi dan Alokasi Tenaga Kerja Berdasarkan SNI 03-2002. 


\section{Kesimpulan}

\section{BAB IV KESIMPULAN DAN SARAN.}

1. Penentuan jumlah Tenaga Kerja untuk mendapatkan durasi pekerjaan didasarkan pada data-data proyek yang ada dilapangan yang berupa data Jenis Pekerjaan, Volume pekerjaan (Bill of Quantity Project), dan juga penggunaan Koefisien SNI yang telah ditetapkan.

2. Penelitian ini mengunakan metode Precedence Diagram Method (PDM), dan Pengolahan datanya dengan program Primavera Project Planer versi 3.0 yang mempermudah proses monitoring dan controlling serta mempercepat proses updating selama pelaksanaan dilapangan.

3. Berdasarkan analisa perencanaan yang kami lakukan, maka diperoleh perencanaan waktu 1005 Hari, Start date 01 Septeber 2010 dan Finish Date 15 November 2013, dengan mengunakan tenaga kerja rata-rata 41 orang/hari.

4. Output hasil perencanaan adalah berupa tampilan grafis Barchart \& Time schedule yang memperlihatkan aktivitas pekerjaan dalam diagram batang, dan Jaringan Kerja (Network planning)memperlihatkan hubungan saling ketergantungan antar aktivitas pekerjaan dengan lebih jelas berikut jalur kritis untuk dimonitor sehingga tidak terjadi keterlambatan.

5. Jumlah tenaga kerja memiliki hubungan yang berbanding terbalik dengan durasi(waktu). Jika jumlah tenaga kerja diperbanyak atau ditambah maka durasi pekerjaan akan semakin cepat, jika jumlah tenaga kerja dikurangi maka durasi pekerjaan akan semakin lama.

\section{Saran-saran}

1. Perencanaan waktu dan tenaga kerja agar lebih efisien sebaiknya menggunakan program Primavera Project Planner untuk dapat memudahkan dalm perencanaan dan pelaksanaan, kontroling, serta pengabdetan laporan perkembangan dengan cepat.

2.Untuk mengatasi kendala dalam proyek, yang perlu diperhatikan antara lain:

- Tenaga kerja, dengan jalan menambah tenaga kerja atau menambahkan jumlah jam kerja (lembur).

- Metode pelaksanaan, yaitu dengan metode pelaksanaan yang efisien dan menghasilkan kuantitas pekerjaan yang lebih besar dan cepat.

- Peralatan, yaitu dengan jalan menambahkan jumlah peralatan. 


\section{DAFTAR PUSTAKA}

Adiyono, Menghitung Konstruksi Beton untuk pengembangan Rumah Betingkat dan Tidak Bertingkat, Penebar Swadaya, Jakarta 2007.

Badan Standarisasi Nasional (BSN), Standar Nasional Indonesia (SNI) 2002 Kumpulan Analisa Biaya Konstruksi (ABK) Bangunan Gedung Dan Perumahan, 2002

Panitia Teknis Badan Standarisasi Nasional (BSN) Bidang Konstruksi Bangunan, Standar Nasionan Indonesia (SNI) analisa Biaya Konstruksi Bangunan Gedung dan Perumahan, Bandung, 2002.

Ir. Abrar Husen, MT. Manajemen Proyek: Perencanaan, Penjadwalan \& Pengendalian Proyek, Penerbit Andi, Yogyakarta, 2009.

Ir. V. Sunggono KH, Buku Teknik Sipil, Nova, Bandung 1984.

Iman Suharto,. Manajemen Proyek dari Konseptual sampai Operasional (jilid 1), Penerbit Erlangga, Jakarta, 1990.

Iman Suharto,. Manajemen Proyek dari Konseptual sampai Operasional (jilid 2), Penerbit Erlangga, Jakarta, 1990.

Iman Suharto,. Manajemen Proyek dari Konseptual sampai Operasional, Penerbit Erlangga, Jakarta, 1995.

George R. Terry, Manajemen Proyek Profesional, Penerbit Erlangga, Jakarta, 1995.

Nugraha, Paulus, Nathan, Isak dan Sujipto,. Manajemen Proyek Konstruksi, Kartika Yudha, Surabaya, 1986.

Tim Penelitian dan Pengembangan Wahana Komputer, Analisis dan Penjadwalan Waktu dan Biaya Proyek dengan Program Primavera, Salemba Infotek, Jakarta, 2003.

Wulfram I. Ervianto, MT. Teori-Aplikasi Manajemen Proyek Konstruksi, Penerbit Andi, Yogyakarta, 2004. 